University of Nebraska - Lincoln

DigitalCommons@University of Nebraska - Lincoln

Si-Hwang Liou Publications

Research Papers in Physics and Astronomy

November 1988

\title{
Ferromagnetism in metastable 304 stainless steel with bcc structure
}

J. Childress

The Johns Hopkins University, Baltimore, Maryland

Sy_Hwang Liou

University of Nebraska-Lincoln, sliou@unl.edu

C.L. Chien

The Johns Hopkins University, Baltimore, Maryland

Follow this and additional works at: https://digitalcommons.unl.edu/physicsliou

Part of the Physics Commons

Childress, J.; Liou, Sy_Hwang; and Chien, C.L., "Ferromagnetism in metastable 304 stainless steel with bcc structure" (1988). Si-Hwang Liou Publications. 30.

https://digitalcommons.unl.edu/physicsliou/30

This Article is brought to you for free and open access by the Research Papers in Physics and Astronomy at DigitalCommons@University of Nebraska - Lincoln. It has been accepted for inclusion in Si-Hwang Liou Publications by an authorized administrator of DigitalCommons@University of Nebraska - Lincoln. 


\title{
Farromagnetism in metastable 304 stainless steel with bcc structure
}

\author{
J. Childress, S. H. Liou, al and C.L. Chien \\ Department of Physics and Astronomy, The Johns Hopkins Universits, Balimore, Maryland 21218
}

\begin{abstract}
We have studied the consequence of structure on the magnetic properties of 304 stainless steel in two distinct crystalline states. Ordinary 304 stainless steel has an fcc structure and is nonmagnetic at room temperature. By using a vapor quenching method, we have fabricated single phase metastable bec 304 stainless steel which is strongly ferromagnetic. Films a few $\mu \mathrm{m}$ thick have been made by high-rate sputter deposition onto substrates at room temperature or liquid-nitrogen temperature. Vibrating sample magnetometry and ${ }^{57} \mathrm{Fe}$ Móssbauer spectroscopy reveal that the bec phase has a magnetization of $130 \mathrm{emu} / \mathrm{g}$, due largely to the Fe moment. The Curie temperature is found to be excess of $550^{\circ} \mathrm{C}$. Upon subsequent annealing above $550^{\circ} \mathrm{C}$, the metastable bec state transforms back into the usual nonmagnetic fcc phase. The changes in the magnetic properties and the structure of these flms during the transformation are examined.
\end{abstract}

\section{IRTROOUCTIOH}

The diversiffed magnetic properties of pure Fe and Febased alloys is one of the most interesting aspects of magnetism. Ordinary bec (body-centered-cubic) $\alpha$-Fe is strongly ferromagnetic, whereas the fcc (face-centered-cubic) $\gamma$-Fe is not. This structural dependence of the magnetic properties is often observed as well in many Febased alloys. "The mag. netic properties of Fe-based amorphous alloys with high Fe concentration, although different but not unrelated, also exhibit interesting systematics. ${ }^{2}$ For example, amorphous Femetalloid alloys (e.g., Fe-B, Fe-Si, etc.) are strongly ferromagnetic with high Curic temperatures, whereas amorphous Fe-metal alloys (e.g., $\mathrm{Fe}-\mathrm{Zr}, \mathrm{Fe}-\mathrm{Nb}$, etc.) are not. $^{3}$

An interesting case in point is 304 stainless steel (SS). Ordinary $304 \mathrm{SS}$, with a nominal composition of 72 -wt. \% $\mathrm{Fe}, 18$-wt. \% Cr, 8-wt. \% Ni, and 2-wt. \% Min, normally appears in the fcc phase, which is nonmagnetic despite its high Fe content. The metastable bcc phase of 304 SS cannot be obtained by equilibrim methods, but cold-working or low-temperature deformation are known to partially retain this bce state. ${ }^{4}$ By far the most effective way of producing single phase bec $304 \mathrm{SS}$ is through rapid quenching methods, in particular vapor quenching. 5 , Hence, once the bcc phase is obtained, it is possible to examine the properties of $304 \mathrm{~S} S$ in two distinct crystalline states, a stable fec state and a metastable bcc state, as well as the transformation from bce to fcc. A major difference between the bcc and fce 304 SS is their magnetic properties; unlike the fcc phase, the bcc phase is strongly ferromagnetic. In this work, we have examined the magnetic properties of the metastable bcc phase and $_{\text {its }}$ cransformation to the fcc state.

\section{EXPERIRTATAL METHOD}

Thin films of 304 SS were obtained using a high-rate de magnetron sputtering system with a base pressure of $10^{-7}$ Torr, and $4 \mathrm{~m}$ Tor of argon as the sputtering gas. The sputtering targets were machined disks of commercial 304 SS.

a) Present address: ATRT Bell Labs, Murray Hill, NJ 07974.
Pims of a lew $\mu \mathrm{m}$ in thickness were deposited on mica and $\mathrm{Al}_{2} \mathrm{O}_{3}$ substrates kept at liguid-nitrogen temperature or room temperature. No difference was found between samples deposited at these wo substrate temperatures. After deposition, the samples could easily be lifted from the substrates and left free standing. The structure of the films was investigated using a Philips $\mathrm{APD} 320$ difractometer in the $\theta-2 \theta$ geometry, by mounting the substrate-free films on glass. The magnetic properties of the films were determined up to $700^{\circ} \mathrm{C}$ with a vibrating sample magnetometer (VSM) manufactured by Digital Measurements Systems. For structural and magnetic studies as a function of annealing conditions, samples were heated in a high-temperature furmace, up to $800^{\circ} \mathrm{C}$ in an atmosphere of fowing argon. The magnetic transformation was also studied by the Mósbaver effect, in which case, the samples were encased in boron nitride and heated in an evacuated oven. A conventional Mössbaver spectrometer with a ${ }^{57} \mathrm{Co}$ source in a rhodium matrix was used.

\section{RESULTS}

$X$-ray diffraction patterns of the 304 SS target and sputtered $304 \mathrm{SS}$ are shown in Figs. 1 (a) and $1(\mathrm{~b})$. The $304 \mathrm{SS}$ target is essentially fcc, as expected. However, the as-sputtered $304 \mathrm{SS}$ is single-phase bec (iattice parameter $a=2.87$ A) with no evidence of either the fcc phase or the amorphous phase. Thus, by employing a vapor-quench method, such as high-rate sputtering, the metastable bcc phase can be very conveniently fabricated.

The transformation from the metastable bec state to foc state was investigated by annealing the as-sputtered samples at elevated temperatures; each at a specific temperature for 20 min. The $x$-ray difraction pattem was then recorded at room temperature. Two such examples, annealed at 600 and $800^{\circ} \mathrm{C}$, are shown in Figs. $1(\mathrm{c})$ and $1(\mathrm{~d})$, respectively. The sample annealed at $600^{\circ} \mathrm{C}$ exhibits both bec and fcc phases, indicating that a portion of the metastable bcc phase has transformed into the fec phase. At $800^{\circ} \mathrm{C}$ for $20 \mathrm{~min}$, the transformation has been compieted and only the fec phase (latice parameter $a=3.59 \AA$ ) is cound. To more quantita- 

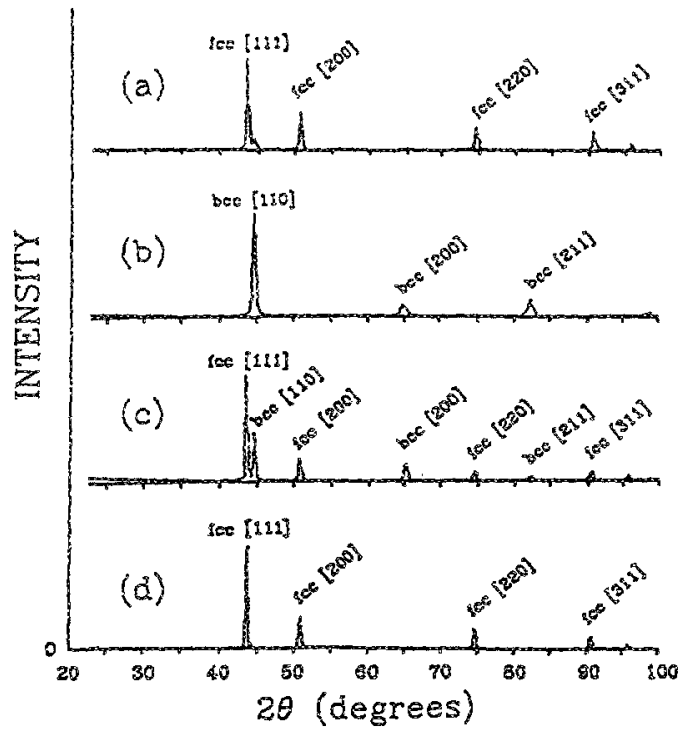

FIG. 1. X-ray diffraction patterns at room temperature of 304 stainless steel: (a) original target material of fec 304 SS, (b) as-sputtered bcc 304 SS, (c) sputtered $304 \mathrm{SS}$ fim anneaied $20 \mathrm{~min}$ a $600^{\circ} \mathrm{C}$, and (d) spurtered 304 SS annealed 20 min at $800^{\circ} \mathrm{C}$.

tively characterize the transformation kinetics, the normal. ized sum of the bcc [110] and bce [200] peaks and the sum of the fcc [111] and fcc [200] peaks are plotted as a function of the annealing temperature, as shown in Fig. 2. It is found that the transformation begins slowly near $500^{\circ} \mathrm{C}$, with a $5 \%$ yield, and quickly reaches $50 \%$ near $550^{\circ} \mathrm{C}$. The transformation is completed near $800^{\circ} \mathrm{C}$.

The fcc phase is essentially nonmagnetic. Indeed, the magnetization of the 304 SS target material is about $1 \mathrm{emu} / \mathrm{g}$ under an external field of $14 \mathrm{kOe}$ [Fig. 3(a)]. The bec phase of the as-sputtered 304 SS, however, is strongly ferromagnetic with a spontaneous magnetization of $130 \mathrm{emu} / \mathrm{g}$ [Fig. 3 (b) ]. Thus, the strong structural dependence of magnetic properties is vividly demonstrated in bec and fec 304 SS. Differences between measurements made with the applied

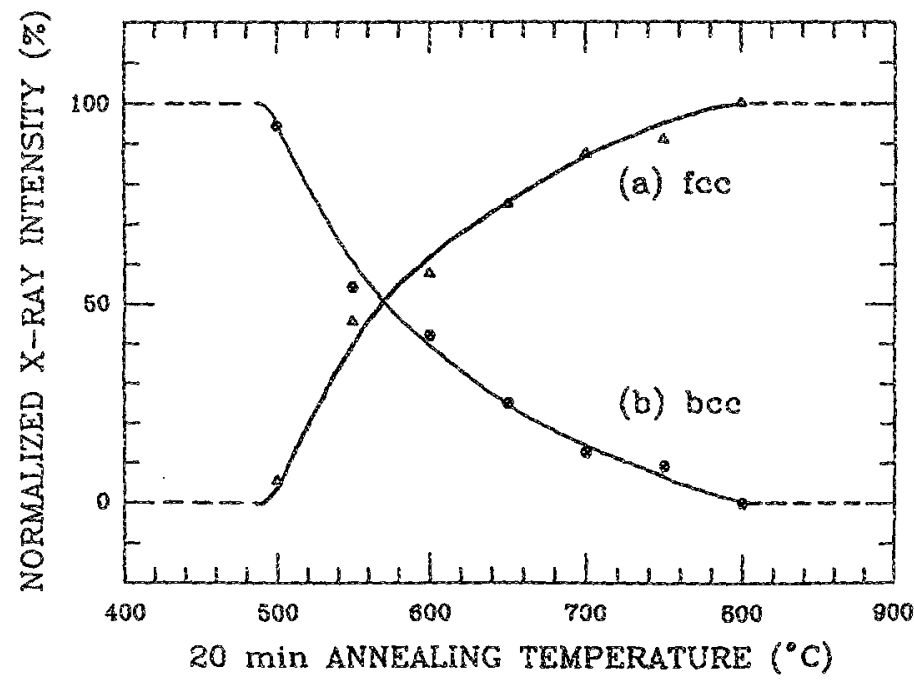

FIG. 2. Normalized sum of the $x$-ray intensities of $(a) f c[111]$ and [200] peaks and $(b)$ bcc [110] and [200] peaks in the $x-$ ray diffraction pattern of sputtered 304 stainless steel, as a function of annealing temperature.

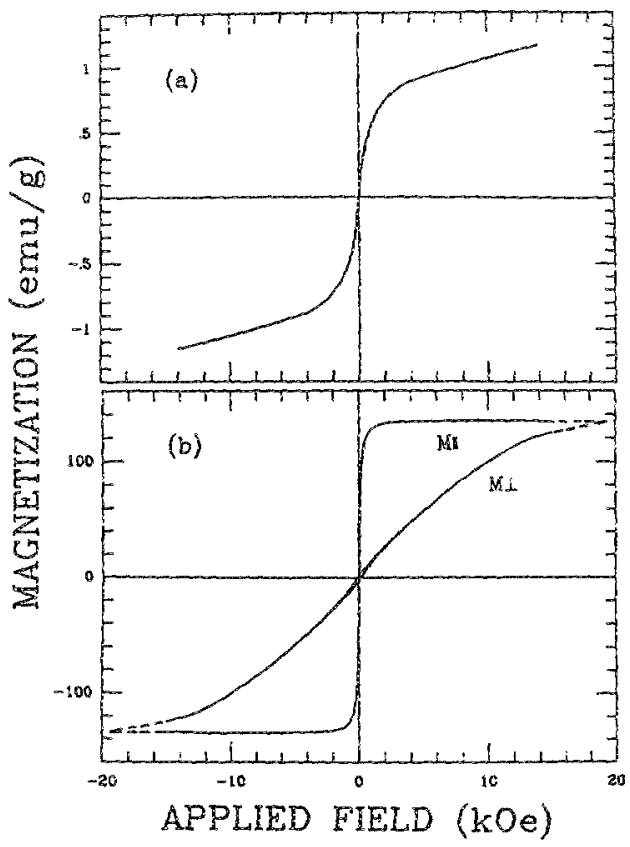

FIG. 3. Magnetic hysteresis loop at room temperature of 304 stainless steel: (a) original target material of fcc 304 SS and (b) as-sputtered bcc 304 SS.

field parallel $\left(M_{4}\right)$ and perpendicular $\left(M_{\perp}\right)$ to the sample plane are mainly the result of the different geometrical demagnetization effects. It is aiso found that the bcc $304 \mathrm{SS}$ is magnetically soft with a coercivity of about $50 \mathrm{Oe}$.

Since the magnetic properties of 304 SS depend critically on the structure being bec or fec, the structural transformation can be directly related to the resulting magnetic properties. The spontaneous magnetization of the sputtered 304 SS sample was measured at progressively higher annealing temperatures $\left(T_{A}\right)$ with the sample in a flowing Ar atmosphere. Each measurement of about 10 min at $T_{A}$ was always followed by a measurement at $30^{\circ} \mathrm{C}$, before heating the sample to the next higher $T_{A}$. The results of the measurements at $T_{A}$ and $30^{\circ} \mathrm{C}$ are shown in Fig. 4 as a function of

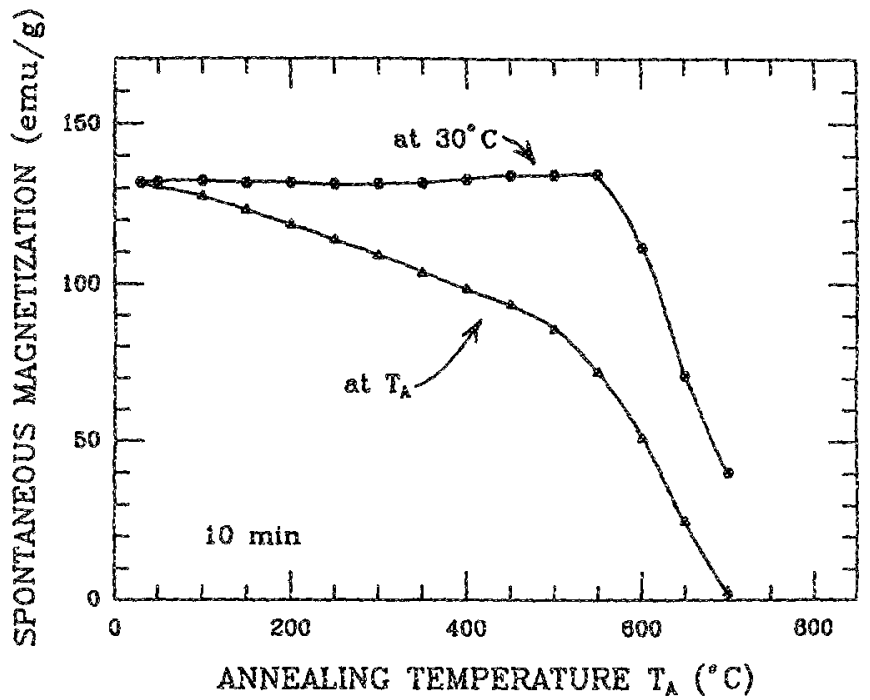

FIG. 4. Spontaneous magnetization of sputtered 304 stainless steel as a function of annealing temperature $T_{A}$, measured at $30^{\circ} \mathrm{C}$ and at $T_{A}$. 
$T_{A}$. It is seen that the spontaneous magnetization at $30^{\circ} \mathrm{C}$ of $130 \mathrm{emu} / \mathrm{g}$ is maintained up to $T_{A}=550^{\circ} \mathrm{C}$. After $550^{\circ} \mathrm{C}$ the magnetization at $30^{\circ} \mathrm{C}$ decreases rapidly, signaling the structural transformation. The sample annealed at $800^{\circ} \mathrm{C}$ is fce and essentially nonmagnetic at $30^{\circ} \mathrm{C}$ with a magnetization of about 1 emu/g under a field of $14 \mathrm{kOe}$, and demagnetization effects can no longer be observed.

Because of the structural transformation commencing at about $550^{\circ} \mathrm{C}$, it is not possible to directly determine the Curie temperature $\left(T_{c}\right)$ of the metastable bcc phase. However, from the temperature dependence of the magnetization, as shown in Fig. $4, T_{c}$ is estimated to be at least $600^{\circ} \mathrm{C}$.

The distinct magnetic properties of the fec and bec states of 304 SS, and the associated structural transformation, have also been fruitfully investigated by Mössbauer spectroscopy. In the nonmagnetic state of the starting fec 304 SS, the Mössbauer spectrum exhibits a single peak as expected. In the assputtered sample of bcc 304 SS, one instead observes a sixline spectrum with a mean hyperfine field of about $255 \mathrm{kOe}$. Pure $\mathrm{Fe}$ ( $\mathrm{bcc} \alpha-\mathrm{Fe}$ ) has a moment of $2.2 \mu_{B}$, a magnetization of $220 \mathrm{emu} / \mathrm{g}$, and a magnetic hyperfine of $330 \mathrm{kOe}$. If we use the magnetic hyperfine field to gauge the Fe moment, the moment in bec $304 \mathrm{SS}$ is about $1.7 \mu_{B}$. Since 304 SS has $72 \%$

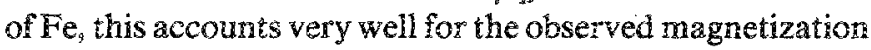
of $130 \mathrm{emu} / \mathrm{g}$. Hence, it can be concluded that in the bec 304 $\mathrm{SS}$, only the $\mathrm{Fe}$ atoms contribute significantly to the magnetization. After the bec 304 SS has transformed completely to the fcc state, the resulting spectrum is once again a single line.

\section{CORCLUSIONS}

We have obtained single-phase bcc thin films of 304 stainiess steel by dc magnetron sputtering. The samples are strongly ferromagnetic and only the Fe atoms contribute to the magnetization. The bcc phase begins to transform to the fcc state at $550^{\circ} \mathrm{C}$, and the transformation is completed after $20 \mathrm{~min}$ at $800^{\circ} \mathrm{C}$. During the transformation the magnetization is directly proportional to the amount of bec phase present. The magnetic properties of the transformed films are very similar to those of the original 304 SS material, i.e., essentially nonmagnetic.

\section{ACKNOWLDGMENT}

This work was supported by ONR Contract No. N00014-85-K-0175.

'See, e.g, T. Moriy, J. Magn. Magn. Mater. 31-38, 10 (1983), and references therein.

${ }^{2}$ See, e.g., K. Moorjani and J. M. D. Coey, Mognetic Glosses (Elsevier, Amsterdam, 1984).

${ }^{5}$ G. Xiao and C. L. Chien, Phys. Rev. B 35, 8763 (1987).

${ }^{4}$ T. Angel, 3. Iron Steel Inst. 177, 165 (1954).

s. D. Dahlgien, Met. Trans. 1,3095 (1970).

T. W. Barbee, B. E. Jacobson, and D. L. Keith, Thin Solid Fims 63, 143 (1979). 